\title{
Sustainable Biodiesel Production from Waste Cooking Oil and Chicken Fat as an Alternative Fuel for Diesel Engine
}

\author{
Ribwar K. Abdulrahman (Msc.) \\ Chemical Engineering Department, Faculty of Engineering, Koya \\ University, Daniel Mitterrand Boulevard, Koya, Kurdistan Region, Iraq
}

doi: 10.19044/esj.2016.v13n3p235 URL:http://dx.doi.org/10.19044/esj.2016.v13n3p235

\begin{abstract}
In recent decade, the demand for fuel as a source of energy has been dramatic. In fact, many oil and gas reservoirs are declining around the world. The use of fossil fuels such as oil, coal, and natural gas is contributing to the phenomenon of global warming. This is because it emits high quantities of carbon dioxide and other greenhouse gases to the atmosphere. Thus, many researchers and energy companies are investigating the production of an environmental friendly fuel that reduces the emission of greenhouse gases. Thus, bio fuel is one of the most obvious alternative sustainable fuels that can be produced from used vegetable oil and animal fats as well. Indeed, it has several advantages. For example, a biodegradable and a renewable energy reduces global warming phenomenon. Thus, this work is an attempt to produce a biodiesel fuel from chicken fat and waste cooking oil. Also, it was found that it is possible to produce biodiesel from chicken fat and waste cooking oils using transesterification reaction method. Furthermore, the process optimization was also adopted; for example, methanol to oil ratio. It has been found that the yield percentages of the produced biodiesel is increased by increasing the amount of methanol. In addition, the maximum conversion to ester could be achieved at methanol: oil ratio about 7:1. at 60 ${ }^{\circ} \mathrm{C}$.
\end{abstract}

Keywords: Biodiesel, bio fuel, renewable energy, chicken fat, waste cooking oils, process optimization

\section{Introduction}

The various researches aimed at finding an alternative fuels for the traditional fossil fuel is increasing recently. However, this has resulted to environmental concern about the greenhouse emission and the global warming phenomenon. Moreover, this has led to the rapid depleting of many 
hydrocarbon reservoirs around the world. Indeed, the researchers have developed several new alternative fuels such as hydrogen and wind energy. However, biodiesel is one of the most popular alternative fuels because it posses several advantages. For instance, it is an environmentally clean energy, and it can be produced from various renewable sources such as vegetable oil and animal fats. Moreover, many researchers have mentioned that biodiesel has a chemical and physical properties that is better than those fuels that is derived from diesels. Therefore, it has a higher lubricating quality and lower sulphur content (Chakraborty \& Sahu, 2014; Maneerung et al., 2016; Frank Gunstone, 2011).

Biodiesels fuels are obtained by the transesterification reaction from either animal fat or used vegetable. Thus, it is made using a process known as transesterification reaction (Pandey, 2009; Ahmad, 2012; Chena et al., 2010). Thus, it is a process of converting vegetable oil or animal fats into a useful material that can power diesel engine. Based-catalysed transesterification reaction processes is the most popular process used to produce it. Moreover, it involves the utilizing of a catalyst and alcohol, usually methanol, to produce methyl-ester or ethyl-ester respectively. Furthermore, biodiesel posses several advantages; for example, it is nontoxic, biodegradable, and has a high heating value that makes it the most favoured choice as an alternative energy source (Frank Gunstone, 2011; Ahmad, 2012). Furthermore, it poses a reduced molecular weight, suitable viscosity, and volatility. Thus, figure 1 shows the reaction mechanism of the transesterification of triglycerides with alcohol (Balat \& Balat, 2010; Nuhu \& Kovo, 2015).

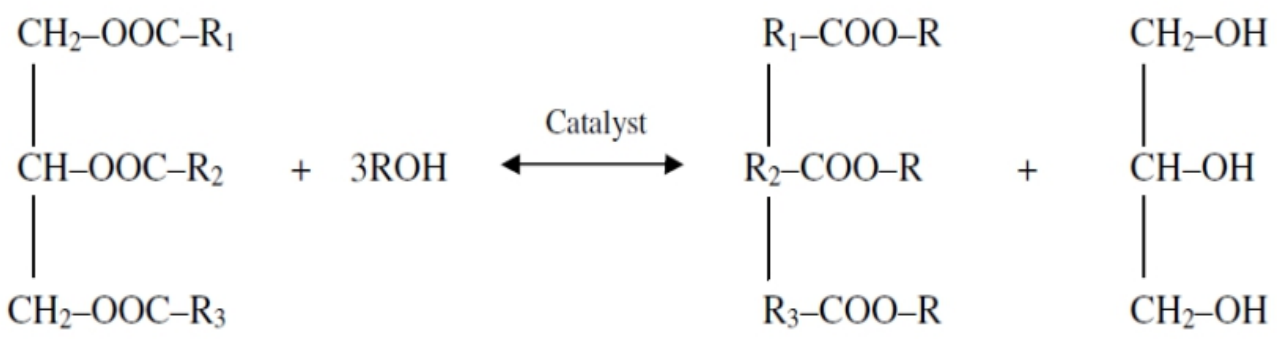

Triglyceride

Alcohol

Esters

Glycerol

(Biodiesel)

Figure 1. Transesterification of triglycerides with alcohol (Nuhu \& Kovo, 2015)

First generation bio fuels have shown that limitations because of the resource used in competition with food applications. Indeed, the use of organic materials such as food and raw material for bio fuel production is creating a conflict. This is because it has a significant effect on the food chain. Also, it encouraged the investigations on the use of non-edible oil and 
fats for producing biodiesel such as waste cooking oil and animal fats. Subsequently, biodiesel may consider a renewable and biodegradable fuel, and they are rich with organic components. Moreover, the use of biodiesel results in a considerable reduction in the emissions of greenhouse gases which include carbon dioxide, carbon monoxide, and sulphur. Additionally, the use of waste oil and fat are well recommended in biodiesel industry and such materials are usually low in terms of cost (Buendía-Tamariz1 et al., 2015).

\section{Research Methodology}

Waste cooking oils and chicken fats were obtained and collected from a local butcher shops and fast food restaurants in Koya city in Iraqi, Kurdistan region. The chicken fats was washed and cleaned with deionised water. Moreover, the solid fat melted between 65 to $70{ }^{\circ} \mathrm{C}$ (Alptekin \& Canakci, 2010; Nuhu \& Kovo, 2015). The melted fat was filtrated to remove any suspended particles and impurities. The waste cooking oil was also filtrated in order to remove its impurities. Then, the melted fats and waste oil was mixed together, and they produce a new fat and oil blend. Furthermore, the experiment was carried out in a laboratory that makes use of $250 \mathrm{ml}$ flasks. However, the flasks was kept in a water bath maintained at $60^{\circ} \mathrm{C}$. This temperature keeps the methanol below its boiling point temperature. Alkali transesterification reaction was used to produce the biodiesel from the oil and fat blend. The $\mathrm{KOH}$ has been dissolved with the needed amount of methanol. This liquid has been poured into the melted chicken fat in a specific flask. Then the methanol and catalyst mixture were added to the liquid oil and fat mixture in a specific flask. The reaction was done at $60^{\circ} \mathrm{C}$ for 30 min with the use of a 700 rpm hotplate magnetic stirrer. Furthermore, figure 2 shows the hotplate magnetic stirrer. Moreover, the reaction was completed and the reaction products were transferred to a separator funnel which separated the products into two layers. Figure 3 shows the separator funnel. Finally, two materials were separated from each other. The bottom of the separator contains the impurities and glycerol, while the top of the separator contains the biodiesel. 


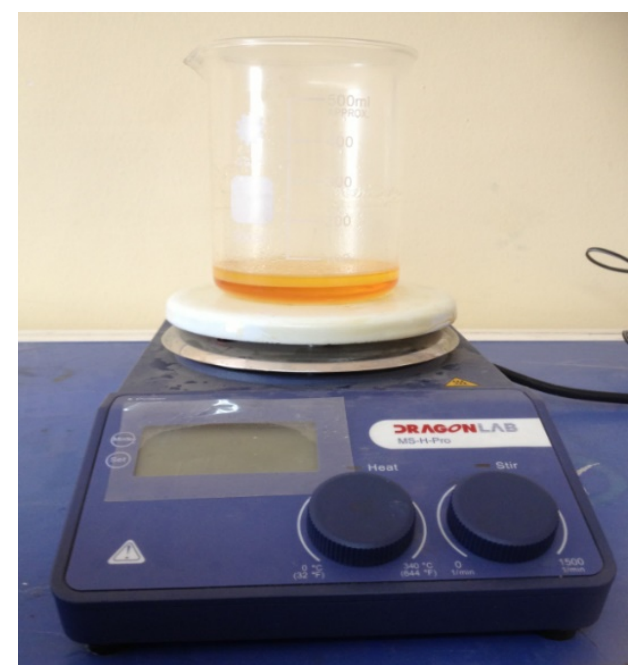

Figure 2. Hotplate magnetic stirrer

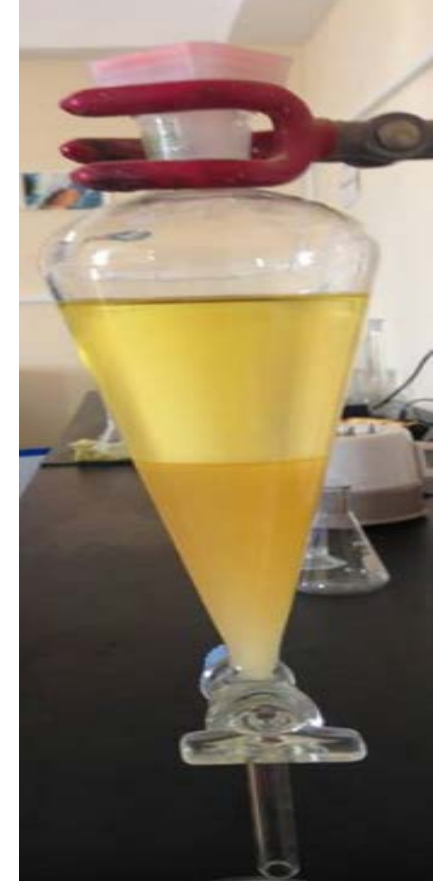

Figure 3. Separator funnel

\section{Results and Discussion}

The Transesterification reaction has been adopted by utilizing a sample of blended WCO and Chicken fat with $1.8 \mathrm{mg} \mathrm{KOH} / \mathrm{g}$ for blended oil and fat. Moreover, this process that was achieved yielded about $83 \%$ with $7: 1$ methanol to oil ratio at $60^{\circ} \mathrm{C}$.

Thus, Table 1 shows some physical properties of produced biodiesel. 
Table 1. Physical properties of produced biodiesel

\begin{tabular}{|c|c|c|}
\hline Properties & Produced biodiesel & ASTM Sanders for Biodiesel \\
\hline Density $15^{\circ} \mathrm{C} \mathrm{kg} / \mathrm{m} 3$ & 882 & $860-900$ \\
\hline Viscosity $40^{\circ} \mathrm{Cmm} 2 / \mathrm{s}$ & 5.924 & $1.9-6$ \\
\hline Cetane Number & 71 & $40 \mathrm{~min}$ \\
\hline Flash point ${ }^{\circ} \mathrm{C}$ & 108 & $54 \mathrm{~min}$ \\
\hline
\end{tabular}

Indeed, the methanol/oil ratio is considered as one of the most important parameters that affect the reaction and biodiesel yield as well. Thus, the process optimization for producing biodiesel was adopted by adopting several methanol/ oil ratios. Figure 1 shows the relationship between several methanol/oil and chicken fat ratio and the yield percent of the biodiesel.

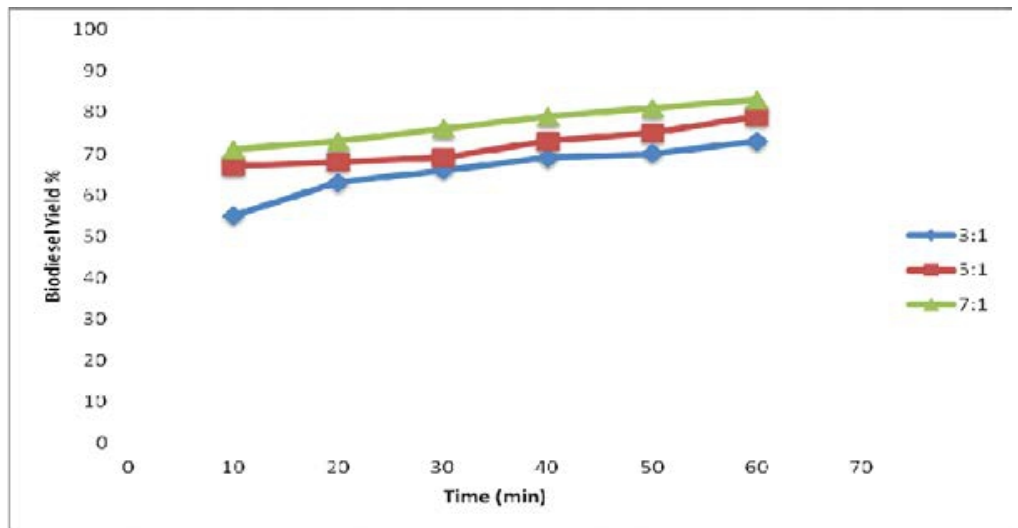

Figure 4. The relationship between the molar ratio of $\mathrm{MeOH} /$ waste oil and chicken fat and biodiesel yield percentages

From figure 4, it can be argued that the yield percentages of the produced biodiesel is increased by increasing the amount of methanol. However, the reaction reaches equilibrium at methanol/oil ratio about 7:1. Also, the maximum conversation to ester could be achieved at methanol: oil ratio about $7: 1$ at $60{ }^{\circ} \mathrm{C}$ with $83 \%$ yield.

\section{Conclusion}

In conclusion, this work is an attempt to produce a biodiesel fuel from chicken fat and waste cooking oil. It can be argued that it is possible to produce biodiesel from chicken fat and waste cooking oils by using transesterification reaction method. Furthermore, the process of optimization is also adopted; for example, methanol to oil ratio. It can be argued that the yield percentages of the produced biodiesel is increased by increasing the amount of methanol. However, the reaction reaches equilibrium at methanol/oil ratio about 7:1. Also, the maximum conversion to ester could be achieved at methanol: oil ratio about $7: 1$ at $60{ }^{\circ} \mathrm{C}$. Furthermore, the 
biodiesel production could be incomplete if the methanol amount is less than the optimal value.

\section{References:}

1. Alptekin, E. \& Canakci, M. (2010). Optimization of pretreatment reaction for methyl ester production from chicken fat, Fuel. 89 (1), PP. 4035-4039.

2. Chakraborty, R. \& Sahu, H. (2014). Intensification of biodiesel production from waste goat tallow using infrared radiation: Process evaluation through response surface methodology and artificial neural network, Applied Energy. 114 (1), PP. 827-836.

3. Balat , M. \& Balat, H. (2010). Progress in biodiesel processing,

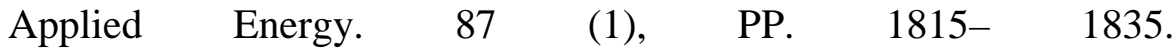
Nuhu, S. \& Kovo, A. (2015). Production and Characterization of Biodiesel from Chicken Fat, Scholarly Journal of Agricultural Science 5(1), PP. 24-26.

4. Maneerung, T., Kawi, S., Dai, Y. \& Hwa, C. (2016 ). Wang Sustainable biodiesel production via transesterification of waste cooking oil by using $\mathrm{CaO}$ catalysts prepared from chicken manure' Energy Conversion and Management 123(1), PP. 478-497.

5. Buendía-Tamariz1,M., Trejo-Calzada, R., Abiola, A., PedrozaSandoval1, A., Jacobo-Salcedo R., \& Reveles-Hernández, M. (2015). Characterization of Biodiesel Produced from Chicken Fat and Pennycress Oil using Different Concentrations of Basic Catalysts, 4 (1) , pp. 127-133.

6. Frank Gunstone (2011). Vegetable Oils in Food Technology: Composition, Properties and Uses. John Wiley \& Sons.

7. Pandey, A. (2009). Biotechnology for Agro-Industrial Residues Utilisation. Texas: Springer Science \& Business Media.

8. Ahmad, M. (2012). Practical Handbook on Biodiesel Production and Properties. Boca Raton: CRC Press.

9. Chena, C., Chena, W.,Changa, C., Ming Lai, b., \& Hsiun Tuc , C. (2010). Biodiesel production from supercritical carbon dioxide extracted Jatropha oil using subcritical hydrolysis and supercritical methylation, The Journal of Supercritical Fluids. 52 (2), PP. 228234.

10. Chakraborty, R. \& Sahu, H. (2014). Intensification of biodiesel production from waste goat tallow using infrared radiation: Process evaluation through response surface methodology and artificial neural network, Applied Energy. 114 (1), PP. 827-836 